\title{
EL CONCEPTO DE LAPORTA DE DERECHOS HUMANOS: MATICES Y DESACUERDOS
}

\author{
Jahel Queralt Lange \\ Universidad Pompeu Fabra
}

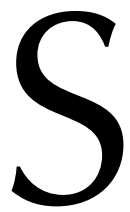

i en el título no aparece la palabra acuerdos es porque las cosas en las que Paco LAPORTA y yo coincidimos, las sabe explicar mejor él y también porque, para qué engañarnos, los filósofos —al menos los analíticos- parecemos estar más cómodos instalados en la crítica y el refinamiento, aunque sea sobre cuestiones menores. Los acuerdos no nos permiten ganarnos la vida. Me alegra mucho poder participar en este homenaje y alimentar la admiración y el vínculo fraterno que me une a los homenajeados y al resto de compañeros de la Universidad Autónoma de Madrid. El trabajo que voy a discutir, «El concepto de derechos humanos», fue publicado por LAPORTA hace casi treinta años ${ }^{1}$. Durante este tiempo la literatura sobre derechos humanos ha crecido a raudales. Y, sin embargo, seguimos a vueltas con algunos de los problemas que plantea LAPORTA —no solo por nuestro afán discutidor, sino porque algunos de ellos son tan centrales como peliagudos-.

El trabajo de LAPORTA está motivado por lo que se conoce como el problema de la inflación de los derechos humanos: la presión por expandir el listado de derechos humanos para conceder a ciertos bienes o intereses humanos la máxima importancia moral y jurídica con el consiguiente riesgo de que el instrumento de los derechos humanos quede devaluado ${ }^{2}$. El problema de la inflación —o incluso la hiperinflaciónno es una cuestión baladí. Debe preocuparnos a todos los que consideramos que los derechos humanos son y deben seguir siendo la lingua franca de la justicia. Pero la solución al mismo no pasa por bunkerizar los derechos humanos existentes negando el reconocimiento de derechos adicionales por el mero hecho de no figurar en la lista inicial. Resulta bastante más razonable adoptar una de estas dos estrategias: $a$ ) incorporar cualificaciones muy exigentes en el concepto de derechos humanos; $b$ ) endurecer las condiciones de justificación de los derechos humanos (NICKEL, 2007) ${ }^{3}$. Ambas opciones nos dan la posibilidad de restringir, sin a priori cerrar, la lista de derechos humanos. LAPORTA opta por la primera estrategia. En su trabajo trata de mostrar que si nos tomamos en serio el carácter universal, absoluto e inalienable de los derechos humanos, debemos ser muy contenidos a la hora de confeccionar una lista de derechos

1 F. LAPORTA, «El concepto de derechos humanos», Doxa, núm. 4, 1987, 22-46.

2 M. Cranston, What Are Human Rights?, London, Bodley Head, 1973; C. Wellman, Real Rights, New York, Oxford University Press, 1995; J. GRIFFIn, On Human Rights, Oxford, Oxford University Press, 2008.

${ }^{3}$ J. Nickel, Making Sense of Human Rights, 2. ${ }^{a}$ ed., Malden, MA, Blackwell Publishing, 2007. 
humanos. De hecho, debemos contenernos tanto que nos vemos obligados a quitarles la etiqueta de humanos a muchos derechos oficialmente reconocidos como tales pero que no reúnen los tres atributos mencionados, según los entiende LAPORTA. Antes de analizar algunos de los problemas del triple test de LAPORTA, quisiera situar su concepción de los derechos humanos.

En este trabajo LAPORTA se compromete con tres posiciones que nos permiten esbozar su concepción de los derechos humanos. La primera es la tesis de los derechos bumanos como razones morales. En este sentido, los derechos humanos son previos a las normas jurídicas que los reconocen. Son, en palabras de LAPORTA, títulos que exigen y justifican establecer ciertas técnicas de protección jurídica pero que existen con independencia de estas ${ }^{4}$. Para un positivista à la BENTHAM esta tesis es un disparate. Sin embargo, es necesario suscribirla para poder afirmar, sin inconsistencias, juicios tan poco controvertidos como que el apartheid de Sudáfrica violaba los derechos de los sudafricanos, a pesar de que no quebrantaba ninguna norma jurídica.

Una de las dificultades de ver los derechos humanos como razones morales es que necesitamos un criterio que nos diga qué tipo de razones son las que dan lugar a derechos humanos —es evidente que no todas lo hacen-. Para atajar este problema LAPORTA suscribe la teoría del interés según la cual la función principal de los derechos es proteger ciertos bienes o estados de cosas que son beneficiosos para el titular del mismo ${ }^{5}$. La combinación de esta tesis con la anterior nos lleva a sostener, que existe un derecho moral cuando un interés individual tiene importancia suficiente como para imponer sobre un agente (el sujeto obligado) el deber de respetar dicho interés ${ }^{6}$. Al afirmar que la noción de interés «no tiene por qué ser algo empíricamente constatable» ${ }^{7}$, LAPORTA se inclina por una noción objetiva de este concepto. Sin embargo, en el texto se cuida mucho de posicionarse metaéticamente. La idea de que existen derechos morales que justifican reconocer derechos legales presupone una noción objetivista de la moralidad ${ }^{8}$ pero es compatible tanto con una posición realista y constructivista.

La teoría del interés presupone que es posible identificar un umbral de importancia a partir del cual un cierto interés individual puede ser considerado básico o fundamental y, en consecuencia, generar un derecho. Como sucede con casi cualquier criterio que depende de un umbral, distinguir un interés básico de otro que no lo es no siempre resulta fácil. Debería resultar evidente que nuestro interés en poder elegir la pasta de dientes que usamos no es básico. Sin embargo, la cosa no está tan clara en relación con intereses más complejos como nuestro interés en vivir en una democracia, disfrutar de la paz o de un medio ambiente saludable. Algunos de estos intereses son los que han justificado la expansión del catálogo de derechos humanos que LAPORTA critica, dando lugar a lo que se conoce como la tercera generación de

${ }^{4}$ F. LAPORTA, «El concepto de derechos humanos», nota 1 supra, 27.

5 F. LAPORTA, «El concepto de derechos humanos», nota 1 supra, 29.

6 J. RAZ, «On the Nature of Rights», Mind, núm. 93, 1984, 194-214, esp. 195.

F. LAPORTA, «El concepto de derechos humanos», nota 1 supra, 29. $117-150$

8 J. Moreso, «El reino de los derechos y la objetividad de la moral», Análisis filosófico, núm. 23, 2003, 
derechos humanos. LAPORTA no ofrece un criterio específico para fijar el umbral de relevancia pero su preocupación por la inflación nos lleva a pensar que, a su juicio, los tres intereses complejos mencionados - y otros que puedan motivar la pretensión de reconocimiento de nuevos derechos humanos como, por ejemplo, el interés en acceder a productos financieros básicos- carecen de la importancia suficiente. En este sentido, no creo arriesgarme demasiado al atribuir a LAPORTA la tesis minimalista sobre los derechos humanos que ancla tales derechos en una concepción «ligera» de lo que es correcto que se limita a especificar las condiciones mínimas de una vida decente? .

Un asunto al que LAPORTA no le dedica demasiado tiempo pero que resulta central para poder terminar de situar su enfoque en la discusión filosófica sobre los derechos humanos es el de la relación que existe entre derechos humanos morales y legales. Respecto a esta cuestión el debate se divide en dos grandes enfoques. Por un lado están las concepciones ortodoxas o bumanistas que sostienen la tesis del espejo según la cual el actual sistema de derechos humanos legales es un intento de cristalizar en normas jurídicas los derechos morales. Por el otro, encontramos lo que se conoce como concepciones políticas de los derechos humanos que niegan el estatus de estos derechos como derechos morales y los definen a partir del rol que cumplen en la práctica del sistema político internacional ${ }^{10}$. Al afirmar que los derechos humanos son, en esencia, derechos morales, LAPORTA se acerca a las concepciones ortodoxas pero sin solaparse del todo con ellas. Se desprende de su texto que aquellos derechos que los textos legales reconocen como humanos pero que no reúnen los requisitos para ser considerados derechos humanos morales, no son derechos humanos en ningún sentido. Los requisitos tan exigentes que fija LAPORTA le llevan a afirmar que los principales tratados sobre derechos humanos en realidad no hablan de derechos humanos y que los tribunales diseñados para aplicar tales instrumentos no deciden sobre derechos humanos ${ }^{11}$. La conclusión sorprenderá a más de uno y desde luego tiene muy mal encaje con la manera que tenemos de concebir nuestras prácticas en este ámbito. La tesis del espejo consigue evitarla distinguiendo entre derechos humanos legales — garantías jurídicas- y derechos humanos morales - títulos de carácter prejurídico-. Es posible - y criticable, según las concepciones ortodoxas- que algunos derechos humanos legales no tengan su correlato moral pero ello no necesariamente ha de llevarnos a afirmar que no son derechos humanos en absoluto. Son derechos humanos legales que carecen de la justificación requerida. A diferencia de la conceptualización de LAPORTA, esta distinción nos proporciona un estándar para evaluar críticamente el actual sistema de derechos humanos legales de un modo que es coherente con la interpretación de nuestras prácticas sobre derechos humanos.

Como anunciaba al principio, la estrategia de LAPORTA para abordar la inflación de los derechos humanos consiste en indagar en tres cualificaciones que tradicionalmente han formado parte de la definición de estos derechos, a saber, su carácter universal,

9 J. Rawls, The Law of Peoples, Cambridge, MA, Harvard University Press, 1999; J. CoHEN, «Minimalism about Human Rights: The Most We Can Hope For?», Journal of Political Philosophy, núm. 12, 2004, 90-213.

${ }^{10} \mathrm{~J}$. Rawls, The Law of Peoples, nota 8 supra; C. BeITZ, The Idea of Human Rights, Oxford, Oxford University Press, 2009.

${ }^{11}$ F. LAPORTA, «El concepto de derechos humanos», nota 1 supra, 41. 
absoluto e inalienable. Veamos algunos de los problemas que afectan a cada una de ellas según las entiende LAPORTA.

Carácter Universal. LAPORTA se basa en este rasgo para ahondar en la idea de que los derechos humanos son derechos exclusivamente morales. Según dice, es imposible sostener que existen derechos humanos legales universales porque no podemos hablar de un sistema jurídico cuyas normas sean universales ${ }^{12}$. Es cierto que en la medida en que haya Estados que no han ratificado los tratados internacionales en materia de derechos humanos y los mecanismos de implementación de los mismos sean tan imperfectos como los actuales, estamos lejos de poder hablar de un sistema jurídico internacional. No obstante, a pesar de eso, podemos afirmar que los derechos humanos son universales en un sentido muy relevante. A diferencia de otros derechos individuales que emanan de los ordenamientos nacionales, los derechos humanos legales obligan a los estados — que los han incorporado en su ordenamiento- a garantizar su contenido a cualquier persona que se encuentre en su territorio. No tienen discreción para vincular la titularidad de estos derechos a la ciudadanía. Por ejemplo, el Decreto-ley 16/2012 mediante el que el gobierno del Partido Popular restringía la cobertura sanitaria de los inmigrantes en situación irregular fue criticado no solo porque vulneraba el derecho humano moral de los inmigrantes a la salud sino también su derecho humano legal reconocido en varios tratados suscritos por el Estado español ${ }^{13}$.

Carácter absoluto. Según LAPORTA, los derechos humanos son derechos prima facie absolutos. En caso de entrar en conflicto con otras exigencias morales, prevalecen sobre estas. La única excepción es el supuesto en el que uno o más derechos humanos entran en conflicto entre sí, en cuyo caso habrá que ponderar entre ellos ${ }^{14}$. De nuevo, no parece que en la práctica los derechos humanos operen así. Los tribunales encargados de aplicar los derechos humanos, lo hacen teniendo en cuenta la llamada doctrina de la proporcionalidad que permite identificar en qué casos está justificado que el Estado interfiera en los derechos humanos de los ciudadanos para perseguir fines distintos a la protección de otros derechos humanos. Por ejemplo, en el caso Hatton y otros v. Reino Unido (STDEH 2001/567) el Tribunal Europeo de Derechos Humanos falló que las molestias que causaba el tráfico nocturno del aeropuerto de Heathrow a la señora Hatton — vecina del mismo - suponían una interferencia en su derecho a la vida privada, pero que dicha interferencia era proporcionada al fin del gobierno de promover el bienestar económico del país - y por tanto estaba justificada-. Si los derechos humanos son absolutos como sostiene LAPORTA, una de dos, o bien el derecho a la vida privada de Hatton debe poder paralizar Heathrow, o bien no debería poder hacerlo porque no es un derecho absoluto y, por tanto, no

12 F. LAPORTA, «El concepto de derechos humanos», nota 1 supra, 33.

13 Concretamente el art. 12 del Pacto Internacional de Derechos Económicos y Sociales; el art. 12 del Convenio sobre la Eliminación de todas las formas de Discriminación contra la Mujer; el art. 24 de la Convención de los Derechos del Niño; el art. 5 de la Convención sobre la Eliminación de todas las formas de Discriminación Racial; el art. 25 de la Convención sobre los Derechos de las Personas con Discapacidad; y el art. 11 de la Carta Social Europea.

14 Aunque LAPORTA no apunta a ninguna regla de ponderación, parece sensato reconocer que entre los derechos humanos existen prioridades. El derecho humano a la vida, por ejemplo, es más importante que el derecho humano a la privacidad y, por tanto, siempre prevalecerá sobre este. 
es un derecho humano. Si LAPORTA se inclina por la primera opción, los derechos humanos se convierten en un lastre del desarrollo y el progreso social. Prácticamente ningún derecho - excepto quizá el derecho a la vida - es absoluto en el sentido de LAPORTA. Los derechos humanos son más bien como los describe GRIFFIN: «resistentes a la ponderación, pero no excesivamente resistentes» ${ }^{15}$. La segunda opción también es problemática. Es importante mantener que existe un derecho humano a la vida privada para poder lamentar que en este caso se haya infringido - aunque sea justificadamente- y obligar al gobierno a poner los medios necesarios para tratar de evitar interferencias como esta en el futuro ${ }^{16}$.

Carácter inalienable. La inalienabilidad de los derechos humanos implica su indisponibilidad por parte del propio titular de los mismos. A primera vista, algunos derechos humanos parecen claramente alienables. Por ejemplo, el derecho humano a la propiedad o el derecho humano al alimento. Tanto la propiedad como el alimento son susceptibles de ser vendidos, intercambiados o destruidos. No obstante, en estos casos podemos sostener que los derechos mencionados protegen otras cosas que sí serían inalienables como la capacidad de ser propietario y el acceso a los medios adecuados para proporcionarse alimento. Pero incluso haciendo esta maniobra interpretativa, no está claro que estos derechos sean inalienables. En realidad, como hemos visto que sucede con el carácter absoluto, es difícil encontrar derechos que posean esta cualidad. Parece razonable que los individuos puedan renunciar a su libertad de movimiento para ingresar en un monasterio o alistarse al ejercito. Tampoco es descabellado que cierto tipo de trabajos como el de agente de seguridad o guardaespaldas exijan limitaciones importantes de la libertad de expresión. LAPORTA acierta cuando señala la tensión entre la inalienabilidad de los derechos humanos y los postulados básicos del liberalismo. Pero su conclusión de limitar los derechos que merecen la consideración de humanos en aras de no agravar dicha tensión no es convincente ya que es difícil encontrar derechos cuya inalienabilidad sea compatible con el liberalismo. De hecho, para muchos liberales, hasta la propia vida debería ser alienable en supuestos en los que una enfermedad terminal grave conlleva dolor y sufrimiento. Probablemente solo sea inalienable el ámbito de la libertad individual que impide a un individuo venderse como esclavo. Siendo así las cosas, parece más sensato revisar el concepto de inalienabilidad y predicarla solo de derechos más abstractos que fundamentarían todo el sistema de derechos humanos como el derecho a ser tratado con igual consideración y respeto por parte del gobierno ${ }^{17}$.

La amalgama de consideraciones hecha hasta aquí suscita una cuestión de carácter metodológico que me gustaría plantear antes de terminar y que tiene que ver con la función de una teoría de los derechos humanos y el rol que debe tener en ella la práctica sobre los derechos humanos. Una concepción que aspire, como parece razonable, a proporcionar un criterio para evaluar la práctica sobre derechos humanos debe distanciarse de dicha práctica pero seguir siendo reconocible como una teoría

15 J. GRIFFIn, On Human Rights, Oxford, Oxford University Press, 2008, 37.

16 G. LETSAS, «Rescuing Proportionality», en R. CRUFT, S. LiAO y M. RENZO (eds.), Philosophical Foundations of Human Rights, Oxford, Oxford University Press, 2015.

17 Vid. NICKEL, Making Sense of Human Rights, nota 3 supra; R. DwORKIn, Taking Rights Seriously, Cambridge, MA, Harvard University Press, 1977. 
sobre la práctica de los derechos humanos. Debe tener en cuenta que dichos derechos han de ser estándares aplicables por nuestros tribunales. Parece que esta teoría se halla en algún lugar intermedio entre las concepciones políticas que se limitan a legitimar el statu quo y la concepción de LAPORTA que se erige totalmente de espaldas a la práctica. 